\title{
A QUESTÃO DO REAJUSTE ANUAL DOS SERVIDORES PÚBLICOS EM FACE
} DA OMISSÃO LEGISLATIVA

\author{
Giovani Clark ${ }^{1}$ \\ Maria Jocélia Nogueira Lima ${ }^{2}$
}

\section{Resumo:}

O trabalho tem como objeto o exame da questão da omissão legislativa dos entes federativos quanto aos reajustes anuais dos servidores públicos e as suas consequências quanto à aplicação do artigo 37, X da Constituição brasileira de 1988, bem como o cabimento ou não de responsabilização civil desses entes da federação face à referida omissão. A pesquisa é eminentemente documental, estribando-se na doutrina, legislação e jurisprudência pátria, possuindo como marco teórico os ensinamentos sobre a Regra da Indexação do Prof. Washington Peluso Albino de Souza, introdutor do Direito Econômico no Brasil.

Palavras-chave: Omissão legislativa. Reajuste. Servidores públicos. Responsabilidade civil do Estado.

\section{THE ISSUE OF THE ANNUAL ADJUSTMENT OF PUBLIC SERVANTS IN THE FACE OF LEGISLATIVE OMISSION}

\begin{abstract}
:
The purpose of this paper is to examine the issue of legislative omission of federative entities regarding the annual readjustments of public servants and their consequences regarding the application of article 37, X of the Brazilian Constitution of 1988, as well as whether or not their civil liability is appropriate. of the federation in view of this omission. The research is eminently documentary, based on the doctrine, legislation and country jurisprudence, having as theoretical framework the teachings on the Rule of Indexation of Professor. Washington Peluso Albino de Souza, introducer of Economic Law in Brazil.
\end{abstract}

key words: Legislative omission. Readjustment. Public servants. State civil liability.

\section{1- INTRODUÇÃO}

O trabalho tem como escopo (objeto) analisar a questão relativa ao reajuste anual de servidor fixado pela Constituição da República Federativo do Brasil de 1988 (CRFB/88),

\footnotetext{
${ }^{1}$ Doutor em Direito Professor do Programa de Pós-Graduação stricto sensu em Direito da PUC Minas e da Graduação da Faculdade de Direito da UFMG. Membro da Fundação Brasileira de Direito Econômico.

Email: giovaniclark@gmail.com

${ }^{2}$ Especialista em Direito Tributário e em Direito Municipal pela PUC Minas, Procuradora Municipal de Belo Horizonte, Mestranda em Direito Público pela PUC Minas. Membro da Fundação Brasileira de Direito Econômico. Email: jocelia.nogueira@pbh.gov.br
} 
especialmente sob o prisma da omissão legislativa em vários entes federativos sobre o tema, bem como as consequências daí advindas, à luz da política orçamentária e da consequente legislação de planejamento estatal delineado pela nossa Lei Maior.

Saliente-se que uma das interpretações jurídicas traduzidas na pesquisa diz respeito a jurisprudências dos tribunais pátrios acerca de ações envolvendo pedidos de servidores públicos de entes federados referentes a reajuste anual de seus vencimentos/proventos, com fundamento no artigo $37, \mathrm{X}$ da Constituição brasileira, com a redação dada pela Emenda Constitucional no. 19/1998, cujo entendimento, de modo geral, tem se pautado no sentido de que se exige lei específica para fins de aumento de remuneração no âmbito do serviço público.

Tal compreensão se justifica, em princípio, porquanto não existindo previsão legal no sentido de garantir aos servidores o reajuste anual, não se pode pretender que seja efetivado judicialmente o referido reajuste fulcrado no artigo $37, \mathrm{X}$ da CRFB/88, com a redação da EC 19/1998, pois o Judiciário não tem função constitucional de legislar.

Ademais, o trabalho ainda investiga o atual posicionamento da jurisprudência do Supremo Tribunal Federal (STF) e a evolução do tema, sem pretensão em exauri-lo, mormente que ainda pende de julgamento a repercussão geral sob o tema n. 19, referenciada abaixo na pesquisa, onde a matéria suscitada aponta para a omissão do Executivo quanto à reposição do poder aquisitivo do servidor em seus vencimentos/proventos, principalmente em tempos de inflação.

A pesquisa é eminentemente documental, estribando-se na doutrina, legislação e jurisprudência pátrias, possuindo como marco teórico os ensinamentos sobre a Regra da Indexação do Prof. Washington Peluso Albino de Souza, introdutor do Direito Econômico no Brasil.

\section{2 - O JUDICIÁRIO E A FALTA DE REAJUSTE ANUAL DOS SERVIDORES PÚBLICOS}

A sociedade brasileira há décadas convive com o fenômeno da inflação, ora maior, ora menor, corroendo o poder aquisitivo dos trabalhadores em geral, da área privada e da área pública e, paralelamente, causando aumentos sucessivos dos preços dos bens e dos serviços. Assim sendo, o poder constituinte originário de 1988 consagrou, expressamente, na nossa Lei Maior atual a Regra da Indexação nos vencimentos dos servidores públicos, no artigo 37, X 
da CRFB/88, com a redação dada pela EC 19/1998, a fim de evitar a redução dos vencimentos dos "trabalhadores" públicos, valorizar os serviços estatais e fortalecer o mercado interno. Ensina o introdutor do Direito Econômico no Brasil, Prof. Washington Peluso Albino de Souza (2017), quanto à referida regra da indexação:

A "indexação" é a prática utilizada em Ciência Econômica pela aplicação de
"indices" para o ajustamento de valores monetários defasados. Em se tratando de
preços, a "indexação" é também impropriamente denominada "correção monetária",
na linguagem corrente, pois não se aplica a corrigir a moeda, e, sim, a reajustar o seu
valor, ou seja, proceder ao reajustamento do "valor nominal" ao "valor real" de seu
poder aquisitivo, em dois momentos diferentes. Determina a quantidade de dinheiro
necessária à aquisição de certo bem, relativamente à quantidade que se fez
necessária anteriormente para essa mesma aquisiçãa. Assim, a casa que tinha o preço "x", em determinado ano, tem hoje o preço "y", maior que o anterior. Seu ex-proprietário, que a vendeu para receber o pagamento dois anos depois, se receber o preço " $x$ ", então contratado, não consegue comprar nem ao menos o lote em que ela se encontra. O vendedor terá empobrecido, independentemente de qualquer medida sua nesse sentido. O comprador terá enriquecido, do mesmo modo, sem que tenha praticado qualquer medida pessoal para esse resultado. Ambos os resultados não dependeram de diligência ou da inépcia de cada uma das duas partes, e sim da política inflacionária posta em prática pelo governo, que alterou o poder aquisitivo da moeda para menos, isto é, modificou o seu "valor real". Não obstante no contrato de compra e venda tenha permanecido o compromisso do pagamento de " $\mathrm{x}$ ", que foi o preço expresso pelo valor nominal da moeda (SOUZA, 2017, p. 127 ).

Dessa forma, a questão suscitada imbrica na denominada "Regra da Indexação" (SOUZA, 2017), incluída expressamente no Texto Constitucional, sendo opção do legislador constituinte relegar à lei ordinária a matéria relativa ao reajuste anual de servidor público, podendo ocorrer, como de fato se mostra atualmente corrente na federação brasileira, a omissão legislativa, iniciativa de exclusividade do Poder Executivo competente, por comando do artigo 61, par. $1^{\circ}$, II, a, da Constituição de 1988, quanto fixa as despesas com pessoal como verba orçamentária. Assim sendo, fica proibida constitucionalmente uma das políticas econômicas mais comuns do regime militar de 1964 a 1985 de redução de investimentos estatais, ou seja, é vedado não corrigir os vencimentos dos servidores públicos em tempos de inflação.

Em razão disso, cabe ao Judiciário, verificando a sua mora quando acionado pela categoria de servidores, determinar as medidas cabíveis, dependendo do pedido circunscrito ao caso em exame, em conformidade ao princípio da congruência ou adstrição contido no artigo 492 do Código de Processo Civil de 2015, que dispõe ser vedado ao juiz proferir 
decisão de natureza diversa da pedida, bem como condenar a parte em quantidade superior ou em objeto diverso do que lhe foi demandado.

Certo é que, em respeito à separação entre os três poderes constitucionais, mostra-se vedado ao Judiciário elaborar ou ditar normas legais, por se caracterizar como usurpação de atribuições específicas do Legislativo e/ou do Executivo, sob pena de afronta à separação e independência dos três Poderes sustentáculos da República Federativa brasileira, entendimento esse que tem prevalecido judicialmente (v.g. TJMG, Processo: Apelação Cível 0011483-57.2015.8.13.0133, pub. 16/07/2019; TJMG Processo: Apelação Cível 000103360.2014.8.13.0175, pub. 16/07/2019; TJSP 1001732-48.2018.8.26.0590, pub. 20/08/2019; TJRS Recurso Inominado no. 71007956394, pub. 31-07-2019) e aplicado à revisão geral anual, quando há omissão legislativa, ao argumento de que somente pode ser assegurada por meio de lei específica, de iniciativa privativa do Executivo, prevista no inciso X do artigo 37 da CBRF/88, com a redação da EC 19/98.

De se vê que, quanto aos servidores federais, somente após a ADI 2.061/DF, cujo julgamento foi em abril do ano de 2001, pelo Supremo Tribunal Federal (STF), houve a edição de lei federal específica para os seus reajustes anuais dos referidos servidores. Fixa a ementa da dita ADI:

EMENTA: AÇÃO DIRETA DE INCONSTITUCIONALIDADE POR OMISSÃO. ART. 37, X, DA CONSTITUIÇÃO FEDERAL (REDAÇÃO DA EC No 19, DE 4 DE JUNHO DE 1998). Norma constitucional que impõe ao Presidente da República o dever de desencadear o processo de elaboração da lei anual de revisão geral da remuneração dos servidores da União, prevista no dispositivo constitucional em destaque, na qualidade de titular exclusivo da competência para iniciativa da espécie, na forma prevista no art. $61, \S 1^{\circ}$, II, a, da CF. Mora que, no caso, se tem por verificada, quanto à observância do preceito constitucional, desde junho/1999, quando transcorridos os primeiros doze meses da data da edição da referida $\mathrm{EC} \mathrm{n}^{\circ}$ 19/98. Não se compreende, a providência, nas atribuições de natureza administrativa do Chefe do Poder Executivo, não havendo cogitar, por isso, da aplicação, no caso, da norma do art. $103, \S 2^{\circ}$, in fine, que prevê a fixação de prazo para o mister. Procedência parcial da ação.

Decisão

O Tribunal, a uma só voz, rejeitou a preliminar suscitada pelo requerido e julgou procedente, em parte, o pedido formulado na ação direta, para assentar a mora do Poder Executivo no encaminhamento do projeto no inciso $\mathrm{X}$ do artigo 37 da Constituição Federal, e determinar a ciência àquele a quem cabe a iniciativa do projeto, ou seja, ao Chefe do Poder Executivo. Votou o Presidente. Falou pelo requerente - Partido dos Trabalhadores-PT - o Dr. Luiz Alberto dos Santos. Ausentes, justificamente, os Senhores Ministros Carlos Velloso (Presidente), Néri da Silveira e Celso de Mello. Presidiu o julgamento o Senhor Ministro Marco Aurélio (Vice-Presidente). Plenário, 25.4.2001. (ADI 2061-7/DF, AÇÃO DIRETA DE 
INCONSTITUCIONALIDADE, Relator(a): Min. ILMAR GALVÃO, Julgamento: 25/04/2001, Órgão Julgador: Tribunal Pleno, Publicação DJ 29-06-2001 PP-00033 EMENT VOL-02037-03 PP-00454, RTJ VOL-00179-02 PP-00587).

Tem-se que só após a ADI acima apontada, verifica-se que houve a edição da Lei no. 10.331, de 18 de dezembro de 2001, regulamentando o inciso X do art. 37 da Constituição brasileira, que dispõe sobre a revisão geral e anual das remunerações e subsídios dos servidores públicos federais dos Poderes Executivo, Legislativo e Judiciário da União, das autarquias e fundações públicas federais.

Porém, a Lei Federal no. 10.331/2001 somente se aplica aos servidores federais, tão apenas, persistindo até a presente data, em inúmeros entes federados (Estados e Municípios), servidores públicos sem o devido reajuste anual, conquanto não há lei a lhes alicerçar a revisão anual constante do artigo 37, X da CRFB, com a redação da EC 19/1998, disposta como norma diretiva, mormente adotada a regra da indexação constitucionalmente, visando a reposição do poder aquisitivo dos vencimentos/proventos dos servidores, em períodos de inflação.

De se vê que, a par disso, a jurisprudência do STF tem se enredado por entender que não cabe ao Judiciário o poder de conceder reajustes ao servidor, sob pena de invasão de competência entre os Poderes, conforme bem delineado na doutrina por Clark e Oliveira (2015) através de profundo estudo sobre o tema.

Por outro lado, dando um passo à frente, o STF entendeu pela existência de repercussão geral da questão atinente ao reajuste anual, editado sob o tema no. 19, em 2007, estando até a presente data sem julgamento do mérito. O julgado analisará o cabimento da condenação da responsabilidade civil do ente federado, face à omissão legislativa para cumprimento do artigo $37, \mathrm{X}$, do texto constitucional:

EMENTA - VENCIMENTOS - REPOSIÇÃO DO PODER AQUISITIVO - ATO OMISSIVO - INDENIZAÇÃO - INCISO X DO ARTIGO 37 DA CONSTITUIÇÃO FEDERAL - RECURSO EXTRAORDINÁRIO - REPERCUSSÃO DO TEMA. Ante a vala comum da inobservância da cláusula constitucional da reposição do poder aquisitivo dos vencimentos, surge com repercussão maior definir o direito dos servidores a indenização.

Decisão: O Tribunal reconheceu a existência de repercussão geral da questão constitucional suscitada, vencido o Ministro Cezar Peluso. Ministro MARCO AURÉLIO Relator. 
Tema - 19 - Indenização pelo não-encaminhamento de projeto de lei de reajuste anual dos vencimentos de servidores público.

Relator: MIN. MARCO AURÉLIO

Leading Case: RE 565089

Descrição: Recurso extraordinário em que se discute, à luz do art. $37, \mathrm{X}$ e $\S 6^{\circ}$, da Constituição Federal, o direito, ou não, a indenização por danos patrimoniais sofridos em razão de omissão do Poder Executivo estadual, consistente no nãoencaminhamento de projeto de lei destinado a viabilizar reajuste geral e anual dos vencimentos de servidores públicos estaduais. (RE 565089 RG / SP - SÃO PAULO, REPERCUSSÃO GERAL NO RECURSO EXTRAORDINÁRIO, Relator(a): Min. MARCO AURÉLIO, Julgamento: 13/12/2007 Órgão Julgador: Tribunal Pleno - meio eletrônico, Publicação DJe-018 DIVULG 31-01-2008 PUBLIC 01-022008, EMENT VOL-02305-14 PP-02913).

\section{3 - A EFETIVAÇÃO DO ARTIGO 37, X DA CRFB/88 COM A REDAÇAO DA EMENDA CONSTITUCIONAL 19/1998, VIA RESPONSABILIDADE CIVIL DO ESTADO, E OS BLOQUEIOS INSTITUCIONAIS}

Denota-se que o entendimento embasado pelo STF de que não é possível o reajuste pelo Judiciário aos servidores, com fulcro no artigo 37, X da Constituição brasileira de 1988, com a redação dada pela EC 19/98, sem a precedente lei específica à espécie, pena de se ferir a competência entre os Poderes, vem sendo seguido pelos tribunais pátrios, como dito alhures, com o fundamento de que a interferência do Judiciário afronta o princípio da separação entre os Poderes republicanos.

Não é demais recordar que não é conferido ao Judiciário o poder de equiparar vencimentos e/ou proventos de servidores públicos com base no princípio da isonomia, matéria já debatida infindáveis vezes em nossos Tribunais pátrios, sendo pacificada pelo Excelso Pretório (STF), a teor da edição da Súmula Vinculante n. 37:

Súmula vinculante 37: não cabe ao poder judiciário, que não tem função legislativa, aumentar vencimentos de servidores públicos sob fundamento de isonomia.

Frise-se, ainda, que a concessão do reajuste anual sem lei específica precedente afrontaria também o princípio da impessoalidade administrativa (art. 37, caput, da CRFB/88), por estabelecer um tratamento diferenciado para o qual inexiste previsão legal, bem como os postulados da moralidade e da eficiência administrativas, por prejudicar o erário e ferir o interesse público nessas estritas condições de omissão legislativa, delineadas no inciso $\mathrm{X}$ do mesmo dispositivo constitucional já aludido. 
Ademais, na doutrina do Prof. Celso Antônio Bandeira de Mello (2010) extrai-se o entendimento acerca da exigência de lei para fixação ou alteração dos vencimentos do servidor:

\begin{abstract}
Finalmente, registre-se a existência de outra importante regra, inspirada pelo mesmo intento de impor procedimentos cautelosos para irrupção de despesas com pessoal e para garantia do princípio da impessoalidade da Administração. Consiste na imposição de que só por lei se fixe a retribuição de cargos, funções ou empregos no Estado e em suas pessoas auxiliares de Direito Público. Assim, o art. 37, X, estabelece que a remuneração dos servidores públicos, inclusive sob a forma de subsídio, somente poderá ser fixada ou alterada por lei específica, observada a iniciativa privativa em cada caso.
\end{abstract}

Também o art. 61, par. 1\%., II, "a", dispõe que a criação de cargos ou empregos públicos ou o aumento de suas remunerações (na Administração direta e nas autarquias) dependem de lei, de iniciativa privativa do Chefe do Poder Executivo. (MELLO, 2010, p. 279).

Nesse aspecto, ressalte-se que, não havendo previsão ou dotação orçamentárias aptas a satisfazer o reajuste anual remuneratório, mostra-se como outra proibição constitucional para o Judiciário avançar no sentido de determinar referido reajuste, porquanto não há lei específica para tanto e nem receita a ser aplicada para o aumento e/ou reajuste propalado, a teor do artigo $169, \S 1^{\circ}, \mathrm{CRFB} / 88$ :

Art. 169. [...].

$\S 1^{\circ}$ A concessão de qualquer vantagem ou aumento de remuneração, a criação de cargos, empregos e funções ou alteração de estrutura de carreiras, bem como a admissão ou contratação de pessoal, a qualquer título, pelos órgãos e entidades da administração direta ou indireta, inclusive fundações instituídas e mantidas pelo poder público, só poderão ser feitas:

I - se houver prévia dotação orçamentária suficiente para atender às projeções de despesa de pessoal e aos acréscimos dela decorrentes;

II - se houver autorização específica na lei de diretrizes orçamentárias, ressalvadas as empresas públicas e as sociedades de economia mista.

Porquanto, a eventual determinação judicial de reajuste anual de servidor público, com fulcro no artigo 37, X da CRFB/88, com a redação dada pela EC 19/1998, porém sem previsão legal, implicaria criação de despesas com a categoria sem iniciativa legiferante do Chefe do Poder Executivo e sem prévia dotação orçamentária, em violação ao artigo acima transcrito de forma literal, assim como do artigo 61, parágrafo $1^{\circ}$., II, a da Constituição brasileira ${ }^{3}$.

\footnotetext{
3 Art. 61 [..]§ $1^{\circ}$ São de iniciativa privativa do Presidente da República as leis que: I - [...]; II - disponham sobre: a) criação de cargos, funções ou empregos públicos na administração direta e autárquica ou aumento de sua remuneração
} 
Assim, a grande questão a ser debatida é referente à ausência de previsão pelos entes federativos com relação à lei de reajuste anual nos vencimentos/proventos do servidor e qual o procedimento a ser adotado, uma vez que, segundo a doutrina e jurisprudência, não é possível discussão ou mesmo decisão do Judiciário que conceda reajuste anual à referida classe sem lei prévia.

A propósito desse tema, BERCOVICI \& MASSONETTO (2006) apontam o descontrole sobre os gastos públicos como fonte do problema aqui estudado:

O problema deste processo de reestruturação das finanças públicas e da estrutura financeira do Estado brasileiro foi o fato de que a recomposição da capacidade de intervenção pública se esgotou na tentativa de controle sobre os gastospúblicos17. A constituição financeira de 1988, que deveria dar suporte para a implementação da constituição econômica de 1988, falhou nesta tarefa. Um dos motivos é a separação que a doutrina e a prática constitucionais pós-1988promoveram entre a constituição financeira e a constituição econômica, como se uma não tivesse nenhuma relação coma outra e como se ambas não fizessem parte da mesma Constituição de 1988. A constituição financeira passou a ser interpretada e aplicada como se fosse "neutra", meramenteprocessual18, com diretrizes e lógica próprias, separada totalmente da ordem econômica e social, esterilizando, assim, a capacidade de intervenção do Estado na economia. Separada da constituição financeira, a constituição econômica de 1988 foi transformada em mera "norma programática". (BERCOVICI \& MASSONETTO, 2006, p. 66-67).

De fato, em compasso aos limites determinados no artigo 169 do Texto Constitucional, a Lei Complementar no. 101/2000, dispõe, lado outro, de forma cogente, imperativa, sobre a necessária obrigatoriedade da sua aplicação quanto ao comando contido em seu artigo 21:

Art. 21. É nulo de pleno direito o ato que provoque aumento da despesa com pessoal e não atenda:

I - as exigências dos arts. 16 e 17 desta Lei Complementar, e o disposto no inciso XIII do art. 37 e no $§ 1$ o do art. 169 da Constituição;

II - o limite legal de comprometimento aplicado às despesas com pessoal inativo.

Parágrafo único. Também é nulo de pleno direito o ato de que resulte aumento da despesa com pessoal expedido nos cento e oitenta dias anteriores ao final do mandato do titular do respectivo Poder ou órgão referido no art. 20.

Não obstante a literalidade do dispositivo em comento, bom que se diga que a Constituição brasileira de 1988 não aponta que o limite legal de comprometimento engloba as 
despesas com pessoal inativo, cabendo salientar, ademais, que de acordo com o "STF (ADIn 2.238-5, DOU 19.02.2003 e DJE 12.09.2008), deve ser interpretado conforme a CF, para que se entenda como "limite legal" aquele previsto em lei complementar (OLIVEIRA, 2014, p. 733)", sendo certo, portanto, que apesar da Constituição Republicana não englobar os inativos, a interpretação dada pelo legislador na Lei Complementar 101/2000 referenciada engloba tais servidores, que já se encontram aposentados, com a chancela do STF.

Assim, a grande questão a ser debatida é referente à ausência de previsão, em vários dos entes federativos, da lei de reajuste anual aos vencimentos do servidor e se caberia condenação dos entes nessas condições ao pagamento de indenização civil à categoria dos servidores/trabalhadores em substituição, pois não é possível a interferência do Judiciário fazendo o papel do Executivo (iniciativa da lei) e legislativo (aprovando a lei), pena de se extrapolar sua competência e desobediência à separação entre os poderes do sistema republicano, mesmo com fincas à implementação do Texto Constitucional.

Repisa-se que o Texto Constitucional é a base do entendimento aqui esposado. E, mormente previsão expressa na Lei Maior brasileira para que o servidor público tenha um reajuste anual sobre os seus vencimentos, necessário que haja a interferência, se acionado, do Judiciário, como órgão de interpretação e aplicação da lei no caso concreto, dentro dos limites do princípio da congruência processual, para que seja efetivada a norma constitucional, neutralizada ante a necessidade de edição de lei a lhe regulamentar a matéria aqui discutida, se pronunciando sobre a possibilidade ou não da condenação do ente federativo omissivo quanto ao disposto no artigo $37, \mathrm{X}$, da CRFB/88.

Ocorre que ao se utilizar o argumento de que não se pode criar custos para a Administração Pública sem a devida contrapartida orçamentária, constata-se que o Judiciário deixa de aplicar um dos maiores princípios constitucionais, qual seja, o da dignidade da pessoa humana (arts $1^{\circ}$, III e 170, Caput da CRFB/88) e no caso dos servidores da administração pública quando seus vencimentos são reduzidos (art. $7^{\circ}$., VI da CRFB/88), por falta de reajustes face às perdas inflacionarias.

A interpretação que se deve dar ao texto constitucional é sistemática, não há comando constitucional que possa ser examinada isoladamente, haja vista a ideia de solidariedade imposta pela própria Constituição (art. $3^{\circ}$, I, da CRFB/88). 
O servidor público, como todo cidadão brasileiro, está sujeito às intempéries econômicas, tendo direito, como qualquer trabalhador, ao seu reajuste salarial, seja o realizado com os sindicatos (empregados e patronais), seja o realizado pela própria legislação (salário mínimo e reajuste de servidores públicos), para que tenha, por consequência, acesso efetivo aos direitos sociais ditados pelo Texto Constitucional (arts $6^{\circ}$ e $7^{\circ}$, da CRFB), inclusive àquele que presta serviço para o Estado e aos cidadãos.

Por outro lado, a nossa Lei Maior de 1988 garantiu expressamente o reajuste dos vencimentos dos servidores públicos ao adotar a Regra da Indexação em tempos de inflação, inviabilizando, assim, a nefasta política econômica de limitação de investimentos estatais recorrente, aplicada a seus "trabalhadores", nos anos 60 a 80 do século passado. Ensina novamente o saudoso Prof. Washington Peluso Albino de Souza sobre referida Regra da Indexação:

\begin{abstract}
Quando a política econômica posta em prática pelas autoridades superiores faz variar o poder aquisitivo da moeda em índices que ultrapassam os admitidos numa economia estabilizada, cabe a essas autoridades assegurar também as medidas defensivas dos interesses privados capazes de serem diretamente atingidos pelos seus efeitos (SOUZA, 2017, p.128).
\end{abstract}

Notadamente às normas programáticas constitucionais, como a do artigo $37, \mathrm{X}$ da CRFB, com a redação da EC 19/1998, o Prof. Gilberto Bercovici (2007) faz uma dura crítica ao que se costuma utilizar a negativa dos direitos do povo brasileiro:

A crítica feita à constituição dirigente pelos autores conservadores diz respeito, entre outros aspectos, ao fato de a constituição dirigente "amarrar" a política, substituindo o processo de decisão política pelas imposições constitucionais. Ao dirigismo constitucional foi imputada a responsabilidade maior pela "ingovernabilidade". O curioso é que os críticos entendem que são apenas os dispositivos constitucionais relativos a políticas públicas e direitos sociais que "engessam" a política, retirando a liberdade de atuação do legislador. Com efeito, os mesmos críticos da constituição dirigente são os grandes defensores das políticas de estabilização e de supremacia do orçamento monetário sobre as despesas sociais. No que respeita à imposição, pela via da reforma constitucional e da legislação infraconstitucional, das políticas ortodoxas de ajuste fiscal e de isolamento da constituição financeira relativamente à constituição econômica, de nenhum dos críticos veio qualquer manifestação de que se estava "amarrando" os futuros governos a uma única política possível, sem qualquer alternativa. Por outras palavras: a constituição dirigente das políticas públicas e dos direitos sociais é entendida como prejudicial aos interesses do país, causadora última das crises econômicas, do deficit público e da "ingovernabilidade"; a constituição dirigente invertida, isto é, a constituição dirigente das políticas neoliberais de ajuste fiscal é vista como algo positivo para a credibilidade e a confiança do país junto ao sistema financeiro internacional. Esta, a constituição dirigente invertida, é a verdadeira constituição dirigente, que vincula toda a política do Estado brasileiro à tutela estatal da renda financeira do capital, à garantia da acumulação de riqueza privada. (BERCOVICI, 2006, p. 72-73). 
Logo, a ideia de que a norma programática, no caso, o reajuste da remuneração do servidor público, determinado anualmente pelo artigo 37, X, da CF com a redação lhe dada pela EC 19/98, só seria aplicável em existindo previsão orçamentária e lei específica e que não haveria a possibilidade da omissão ser vista como ato lesivo aos servidores, mostra-se como uma limitação à concretude do Texto Constitucional. Porém, por uma ótica, é possível examinar o tema, à luz da responsabilidade civil do Estado (art. 37, par. 6º da CRFB), gerando em consequência a indenização àqueles trabalhadores da área pública, com o objetivo explícito e literal de se recompor as perdas aquisitivas do poder da moeda, devido à inflação, aplicando ainda o direito fundamental estribado na ameaça ou lesão ao direito (art. $5^{\circ}, \mathrm{XXXV}$ da CRFB/88), e a partir do qual cabe, por certo, a análise do Judiciário.

O argumento de mínimo existencial em uma sociedade como a brasileira, de extrema desigualdade, a fim de restringir direitos/liberdades constitucionais, além de ser um argumento liberal (BERCOVICI, 2007), ainda faz com que o servidor público não possa exercer um direito constitucional.

\begin{abstract}
Alguns dos mais influentes dentre os autores que defendem o mínimo existencial partem de uma perspectiva liberal e individualista de garantia mínima pelo Estado de condições de existência humana para o exercício das liberdades. Estes autores, equivocadamente, excluem ou limitam a presença dos direitos econômicos e sociais como fundamento deste mínimo existencial. Aliás, é curioso notar como nossos liberais se utilizam tranquilamente, embora de modo velado, sem muitas referências explícitas, do discurso conservador e fascistizante de Carl Schmitt para afirmarem categoricamente que direitos sociais não são direitos fundamentais. Estes autores defendem o mínimo existencial como proteção negativa em relação à intervenção do Estado e, ao mesmo tempo, como algo garantido pelas prestações estatais por meio de políticas públicas focalizadas, não-universalizantes. Afinal, as políticas públicas para efetivação dos direitos sociais são entendidas como não-obrigatórias. E mais: afirmam também que a extensão da lógica dos direitos de liberdade aos direitos sociais fatalmente conduziria à ingovernabilidade. (BERCOVICI, 2007, 460-461)
\end{abstract}

Portanto, a Lei Maior brasileira de 1988 é o ponto de referência e vinculante do Judiciário nacional, não havendo porque se afastar a possibilidade da condenação por responsabilidade civil do Estado ante a sua omissão legislativa, à mingua do simples argumento, que até agora se tem apontado, acerca da não implementação da determinação contida no artigo 37, X da CRFB//88, com a redação dada pela EC 19/98, com a sua neutralização consequente. 
Certo é que não há sequer se falar em ausência de legislação específica sobre o reajuste do servidor, ou ausência de previsão orçamentária para que a dita norma constitucional seja aplicada. Ademais, inviabilizar também a responsabilidade civil estatal no caso em tela é novamente bloquear institucionalmente a efetivação dos ditames constitucionais.

Por bloqueios institucionais entende-se o processo político- -econômico de
construção de barreiras - no âmbito do Executivo, Legislativo ou Judiciário - que,
de forma direta ou indireta, promovam a obstrução dos instrumentos jurídicos e
políticos capazes de transformar a realidade econômica. Em outras palavras, os
bloqueios institucionais são obstruçães políticas e econômicas que imobilizam as
estratégias normativas de materialização da constituição brasileira de 1988 e real
consolidação de um Estado Democrático de Direito. Propomos aqui, então, que a
efetiva compreensão sobre as causas da baixa efetividade da Constituição deve
passar, necessariamente, sobre a reflexão de como operam e se reproduzem os
seguintes bloqueios institucionais relacionados à Constituição Econômica:
a) Bloqueios institucionais que buscam inibir os processos de mudança da realidade
econômica via a supressão do texto constitucional; b) Bloqueios institucionais que
imobilizam os instrumentos de transformação social em razão da omissão de
regulamentação constitucional; c) Bloqueio institucional que, a despeito de não
alterar o texto constitucional, inviabilizam a sua efetivação em razão da
implementação de uma Economia Política da Austeridade (CLARK, CORRÊA,
NASCIMENTO, 2017, p. 687-688).

Aliás, a par disso, se se for considerar que a inexistência de previsão legal conforme artigo 37, X da Constituição brasileira de 1988 para fins indenização do servidor público, por falta de reajuste anual por omissão legislativa, a questão jurídica estaria enterrada, sem se analisar de forma sistêmica a matéria, significa dizer que não havendo previsão orçamentária ou mesmo diretrizes orçamentárias a respeito do tema, não se poderia, absurdamente, exigir efetivação de qualquer tutela jurisdicional, mesmo quando demonstrado a lesão ao direito subjetivo do servidor por omissão do Chefe do Executivo local ou estadual, lesão esta perpetuada a cada ano, trazendo consequências nefastas às categorias de servidores, com a corrosão irremediável da sua moeda e do seu poder de compra e subsistência.

Repise-se que cabe ao Executivo, quando se trata do planejamento legal de suas políticas públicas, inclusive as econômicas, a inclusão na Lei do Plano Plurianual (PPA), Lei de Diretrizes Orçamentárias (LDO) e Lei Orçamentária (LO), legislação planejadora por essência, prevê o reajuste da remuneração do seu servidor público, tendo em vista o mandamento constitucional, cuja finalidade, entre outras é o da distribuição da riqueza, a não redução do poder aquisitivos de servidores, do desenvolvimento, da estabilidade econômica (SOUZA, 2017). 
Se o objetivo a atingir é o "crescimento", o "desenvolvimento", o tipo de "distribuição de riquezas" e a "qualidade de vida", a "estabilidade econômica", ou qualquer outro, o Direito Econômico oferece as normas jurídicas que levem ao resultado almejado, procurando ajustar, pelo Planejamento, as medidas de política econômica à 'ideologia". Esta será definida "politicamente" para, só então, traduzirse no texto constitucional que será "trabalhado" pelo Direito Econômico, [...]. (SOUZA, 2017, p. 376)

Atente-se que os servidores públicos atuam como prestadores de serviços públicos, portanto a bem do interesse público e de toda a coletividade:

\begin{abstract}
As necessidades coletivas são satisfeitas por meio de serviços de interesse geral, que são denominados públicos. Dessa forma, sempre que o Estado presta um serviço de interesse geral, mobilizando pessoas e bens, para satisfazer às necessidades coletivas, realiza serviço público. Assim, serviço público é todo aquele imprescindível à coletividade e, como tal, declarado pelos poderes competentes, cuja prestação está a cargo do Estado. (MATIAS-PEREIRA, 2009, 125-26).
\end{abstract}

De outro lado, cada vez mais se dissemina, senso comum, que o servidor público é uma categoria a ser extinta, discurso rotineiro na escala mundial do capitalismo improdutivo em que vivenciamos atualmente (DOWBOR, 2017), relegando a lugar nenhum a obviedade de que o trabalho é um bem que se vende em prol de um salário garantido e digno, inclusive dos servidores públicos, nesses tempos de neoliberalismo de austeridade (NUNES, 2012), onde os mesmos sempre são acusados de inchar a máquina pública e dilatar os gastos estatais. Explica Feliciano (2019) quanto ao aumento dos servidores públicos brasileiros, baseado em estudo publicado pelo IPEA - Instituto de Pesquisa Econômica Aplicada no final de 2018:

Neste ponto, considerando os principais dados extraídos da pesquisa do Ipea, podemos concluir que nenhuma somatória ou índices apresentados, podem ser lidos ou vistos individualmente e muito menos dissociados de toda realidade brasileira.

Se partirmos para uma análise isolada sobre a informação que nos últimos 20 anos o serviço público teve um aumento de $83 \%$ de vínculos, não estaríamos considerando que ao longo das mesmas duas décadas também houve significativo aumento da população nacional.

De acordo com a última estimativa apresentada pelo Instituto Brasileiro de Geografia e Estatística - IBGE, em julho de 2018, a população brasileira cresceu $21 \%$ entre 2001 e 2017, passando de 172,3 milhões, para 208,5 milhões de habitantes.

Neste sentido, não podemos entender que o serviço público se encontra "inchado", pois com uma soma que ultrapassa 200 milhões de habitantes no país, significa que a cada dia a população necessita cada vez mais de serviços básicos, como segurança, saúde e educação. Apenas estas três áreas do funcionalismo público, representa aproximadamente $60 \%$ de todo serviço público. 
Assim, resta claro que o puro aumento da sociedade representa o evidente crescimento da procura por serviços públicos. Em contrapartida, é notória a existência de uma política pública voltada para o "encolhimento do Estado", que automaticamente reflete sobre a eficiência dos serviços prestados para a população. (FELICIANO, 2019).

Ademais, os servidores públicos, enquanto prestadores de múltiplos serviços estatais, são fundamentais à existência da sociedade, da democracia e do próprio Estado. Assim sendo, não podem ter seus vencimentos corroídos pela inflação e o poder aquisitivo reduzido, tal pratica significa, dentre outras coisas, preconceito a uma grande categoria de "trabalhadores", afronta a regra da indexação (SOUZA, 2017,) bloqueio institucional a efetivação do texto constitucional, via omissão legislativa. Explicam os professores Giovani Clark, Leonardo Alves Corrêa e Samuel Pontes do Nascimento (2017) sobre o bloqueio institucional da constituição brasileira por intermédio da omissão legislativa:

O bloqueio institucional também pode se manifestar em razão da omissão regulatória, ou seja, a negligência política, do Poder Legislativo ou do Executivo, em criar normas que tornam exequíveis mandamentos constitucionais. Em regra, a omissão regulatória é um reflexo da articulação e alinhamento de forças políticas que possuem, em comum, o poder de vetar a propositura, o debate ou a votação de determinadas matérias constitucionais (CLARK, CORRÊA, NASCIMENTO, 2017, p. 691)

Assim sendo, em uma interpretação sistemática da nossa Lei Maior, e não em pedaços, o não reajuste anual dos vencimentos dos servidores públicos em tempos de inflação é uma política econômica pública de limitação de investimentos estatais vedada pelo Texto Constitucional e, portanto, é necessário que o Judiciário não se omita, realizando a justiça distributiva e, mitigando a fragrante violação da Constituição brasileira, impondo a responsabilidade civil do Estado a fim de indenizar os "trabalhadores" estatais pelas perdas anuais do poder aquisitivo de seus vencimentos, via inflação, acarretada por omissão legislativa.

\section{4 - CONSIDERAÇÕES FINAIS}

Inafastável é o fato de que ainda não foi julgado o mérito da repercussão geral reconhecida no STF no Leading Case: RE 565089, cujo tema 19 dispõe sobre a Indenização por danos patrimoniais pelo não-encaminhamento de projeto de lei de reajuste anual dos vencimentos de servidores públicos e em que é Relator: MIN. Marco Aurélio de Melo. 
Lado outro, tem-se que não há, em princípio, por parte dos chefes do Poder Executivo dos entes federados brasileiros, a obrigação de aplicar sem precedente legal o comando insculpido no artigo 37, X da Constituição brasileira de 1988, com a redação lhe dada pela EC 19/98, ou seja, a necessidade premente dos servidores terem a reposição do poder aquisitivo dos seus vencimentos/proventos todos os anos, evitando assim a sua corrosão pela inflação.

Não se olvide, no entanto, que existe a necessidade de se garantir o mínimo existencial para cada pessoa, conforme foi garantido pelo Estado Democrático encetado pela nossa Constituição de 1988, nos direitos fundamentais ali descritos, especialmente no que toca aos direitos fundamentais dos trabalhadores, incluindo-se os servidores públicos. Portanto, é premente por parte do Excelso Pretório a declaração da responsabilidade civil dos entes federativos, ante a omissão legislativa, de não concessão do reajuste anual aos servidores públicos ditado pelo Texto Constitucional e, por consequência, a sua condenação ao pagamento de indenização por danos patrimoniais, quiçá morais, por referida omissão propalada.

Por fim, o bloqueio institucional de nossa Lei Maior enseja a insegurança jurídica aos servidores públicos e retira da legislação planejadora estatal um de seus conteúdos necessários, deixando-se assim de se efetivar a concretude da Constituição Republicana Federativa Brasileira de 1988, sobretudo nesses dias difíceis de neoliberalismo de austeridade.

\section{5 - REFERÊNCIAS:}

AVELÃS NUNES, Antônio José. A Crise Atual do Capitalismo: capital financeiro, neoliberalismo, globalização. São Paulo: Revista dos Tribunais, 2012.

BERCOVICI, Gilberto; MASSONETTO, Luiz Fernando. Constituição Dirigente Invertida: A Blindagem da Constituição Financeira e a Agonia da Constituição Econômica. Boletim de Ciências Econômicas, vol. XLIX. Coimbra: Universidade de Coimbra, p. 57-77, 2006. Disponível em: <https://digitalisdsp.uc.pt/bitstream/10316.2/24845/1/BoletimXLIX_Artigo2.pdf?ln=pt-pt > Acesso em 21 e 28 ago 2019.

Constituição econômica e dignidade da pessoa humana. Revista da Faculdade de Direito, Universidade de São Paulo, v. 102, p. 457-467, 1 jan. 2007. Disponível em: <http://www.revistas.usp.br/rfdusp/article/view/67764/70372 > Acesso em 21 ago 2019. 
BRASIL, Constituição da República Federativa do Brasil. http://www.planalto.gov.br/ccivil 03/constituicao/constituicao67.htm

BRASIL, lei complementar no. 101, de 04 de maio de 2000, acesso em 22.08.2019, http://www.planalto.gov.br/ccivil_03/leis/lcp/lcp101.htm.

BRASIL, lei no. 10.331, de 18 de dezembro de 2001, acesso em 22.08.2019, http://www.planalto.gov.br/ccivil_03/LEIS/LEIS_2001/L10331.htm.

CLARK, Giovani.; CORREA, Leonardo Alves.; NASCIMENTO, Samuel Pontes do . A Constituição Econômica entre a Efetivação e os Bloqueios Institucionais. Revista da Faculdade de Direito da UFMG, v. 71, p. 6777 -700, 2017.

CLARK, Giovani; OLIVEIRA, Flávio Freire de. Aspectos Jurídicos da Revisão Geral Anual da Remuneração dos Servidores Públicos e Agentes Políticos. In: Giovani; CORRÊA, Leonardo Alves; NASCIMENTO, Samuel Pontes do (org.). Direito Econômico em Debate. São Paulo, LTr, 2015.

DOWBOR, Ladislau. A Era do Capital Improdutivo: Por que oito famílias tem mais riqueza do que a metade da população do mundo? São Paulo. Autonomia Literária. 2017.

FELICIANO, Carlos Eduardo M. O Funcionalismo Público no Brasil. Migalhas, 18.01.2019, acesso em 22.08.2019, em https://www.migalhas.com.br/dePeso/16,MI294367,41046$\mathrm{O}+$ funcionalismo+publico+no+Brasil.

MATIAS-PEREIRA, José. Finanças Públicas: a política orçamentária do Brasil, 4a . Ed., São Paulo, ed. Atlas, 2009.

MELlO, Antônio Bandeira de. Curso de Direito Administrativo. 27a . Ed., São Paulo, Malheiros Editores, 2010.

OLIVEIRA, Regis Fernandes de. Curso de Direito Financeiro. $6^{\text {a }}$. Ed., São Paulo, Editora Revista dos Tribunais, 2014.

SOUZA, Washington Peluso Albino de. Primeiras Linhas de Direito Econômico. $6^{\text {a }}$. Ed., São Paulo, LTr, 2017.

Supremo Tribunal Federal, ADIn 2061/DF, acesso em 22.08.2019, http://stf.jus.br/portal/jurisprudencia/listarJurisprudencia.asp?s1=\%28ADI\%24\%2ESCLA\%2 $\mathrm{E}+\mathrm{E}+2061 \% 2 \mathrm{ENUME} \% 2 \mathrm{E} \% 29+\mathrm{OU}+\% 28 \mathrm{ADI} \% 2 \mathrm{EACMS} \% 2 \mathrm{E}+\mathrm{ADJ} 2+2061 \% 2 \mathrm{EACMS} \% 2$ $\mathrm{E} \% 29 \&$ base=baseAcordaos\&url=http://tinyurl.com/lrj5q2u.

Supremo Tribunal Federal, repercussão geral tema no. 19, RE 565089, acesso em 21.08.2019, http://stf.jus.br/portal/jurisprudenciaRepercussao/listarProcesso.asp?PesquisaEm=tema\&Pesq uisaEm=controversia\&PesquisaEm=ambos\&situacaoRG=TODAS\&situacaoAtual=S\&txtTitu loTema=reajuste $\% 20$ anual\&numeroTemaInicial=\&numeroTemaFinal=\&acao=pesquisarProc esso\&dataInicialJulgPV $=\&$ dataFinalJulgPV $=\&$ classeProcesso $=\&$ numeroProcesso $=\&$ ministro $=\&$ ordenacao $=$ asc $\&$ botao $=$ 
Tribunal de Justiça de Minas Gerais, visitado em 18.08.2019, www.tjmg.jus.br.

Tribunal de Justiça do Estado de São Paulo, visitado em 18.08.2019, www.tjsp.jus.br. 